\title{
Examining Online Posters on Cervical Cancer through the Lens of Extended Parallel Processing Model
}

\author{
Prof. Levi Chinaka Nwodu ${ }^{1}$, Chinwe Beatrice Ezeoke, PhD $^{2^{*}}$, Nonye Benedeth Ezeaka, PhD $^{\mathbf{1}}$ \\ ${ }^{I}$ Department of Mass Communication, Chukwuemeka Odumegwu Ojukwu University, Igbarim Campus \\ ${ }^{2}$ Department of Mass Communication, Nnamdi Azikiwe University, Awka, Anambra State, Nigeria.
}

*Corresponding Author: Chinwe Beatrice Ezeoke, PhD, Department of Mass Communication, Nnamdi Azikiwe University, Awka, Anambra State, Nigeria.

\begin{abstract}
The study focused on the assessment of online posters on cervical cancer messages. The emphases were to ascertain the degree of threat and the dominant pattern of efficacy contained in the messages. Content analysis was used to determine the level of threat played up in the online posters as well as the dominant pattern of efficacy contained the posters. The population for the study was the 26 posters which have Nigerian sources indicating that the posters emanate from Nigeria. The population is considered not too large for the researchers to manage as such census method was used. Data obtained for the study were analyzed using tables and percentages. Findings showed that online poster messages on cervical cancer did not emphasize threat in the posters studied, it was also found that efficacy messages (i.e. preventive measures) were minimal in the online posters studied. Based on the findings, the researchers recommended among other things that development and health communication practitioners can develop effective fear appeal messages by increasing references to the severity of the threat (i.e., the magnitude of harm and one's vulnerability to the threat) and also promote efficacy (i.e., belief that the recommended response can work in averting the threat) in the online poster message on cervical cancer in order to achieve the right attitudinal change, in line with the prescriptions of extended parallel processing model. Based on the outcome of the study, the researchers developed a high threat-high efficacy message acceptability model as contribution to knowledge and practice. The model succinctly states that health advocacy messages need to increase threat and efficacy as well as create a balance between perceived threat and perceived efficacy for a positive attitude which will lead to adoption.
\end{abstract}

\section{INTRODUCTION}

The magnitude of deaths in women recorded globally as a result of cervical cancer are largely due to unhealthy behaviours (WHO, 2014, 2015), hence the main objective of health promoting information is to enlighten, encourage and motivate people to engage in desirable health-promoting behaviours (Riet \& Ruiter, 2013). Health communication campaigns represent a viable and important tool for influencing public health (Noar, 2006). A number of health communication studies especially the most recent meta-analysis of about 100 experimental studies on fear appeals have revealed that when perceptions of efficacy (i.e., beliefs about whether one is able to do an effective recommended response to avert a threat) are taken into account, when designing a health communication message, fear appeals have an even stronger effect, such that the greater the fear aroused, threat perceived, the greater the behavioral change as long as perceived efficacy is high (Tannenbaun, Helper Zimmerman, Jacobs, Wilson \& Albarracin 2015; Grifin, 2015; Witte \& Allen, 2000; Morman, 2000; Smalec \& Klingle, 2000; Stephenson \&Witte, 1998; Clarke, 1998; Witte, Berkowitz, Cameron,\& Lillie, 1998).

Witte (1994) defined fear appeals as persuasive messages that scare an audience into adopting a recommended response. According to Dillard, Plotnick, Godbold, Freimuth, \& Edgar (1996); Maddeux \& Rogers (1983) fear appeals are persuasive messages that attempt to arouse fear by emphasizing the potential danger and harm that will befall individuals if they do not adopt the messages' recommendations. Tannenbaun, Helper Zimmerman, Jacobs , Wilson and Albarracin (2015) aver that fear appeals are particularly effective when the communication depicts relatively high amounts of fear, includes an efficacy message, stresses severity and susceptibility, recommends onetime only behaviors, and targets audiences that include a larger percentage of female message recipients.. It then presupposes that effective health campaign design can lead to desired health behaviour. However, several authors have argued that promoting threatening health information 
without effective and/or clear recommendation on how to avert the threat, the effectiveness of the information will be limited by defensive reaction (Ruiter, Abraham, and Kok, 2001; Witte, 1992, 1994). Cervical cancer, according to WHO (2015), is the fourth most common cancer in women with an estimated 528,000 new cases worldwide and 270,000 deaths in 2012 (this is the current statistics as the American Cancer Society responsible for projecting new cancer cases and deaths says that cancer incidence and mortality data lag four to five years behind the current year https://www.cancer,org ). West Africa is on the borderline at the high risk of 29.3 percent (Afri-Dev, 2014). In Nigeria, it is the second most common female cancer, with an age-standardized incidence rate of 34.5 per 100,000 and incidence/morality ratio of 0.6. While the incidence is decreasing in the developed countries due to effective health communication campaigns, (Anderson, Mullins, Siahpush, Spittal, and Wakefield, 2009), it is on the increase in most developing countries (Jedy-Agba, Curano, Ogunbiyi, et al, 2012). In Nigeria for instance, research evidence shows that 26 women die daily as a result of cervical cancer and its complications (Ndikom \& Ofi, 2012). This represents only the reported cases as many unreported cases may abound.

The result of women's non-participation in screening programs is the key reason for the much higher cervical cancer incidence in developing countries (Chia, Udzua and Ugese, 2016). There is need for effective campaign on cervical cancer to sensitize women on the importance of screening for early detection and treatment. Thus, a common response to non- utilization of cervical cancer campaign advocacy is lack of awareness. The most common reasons given for not doing the test were; not deeming the test necessary, not knowing where the test could be done and feeling of not being at risk of developing cervical cancer (Ubajaka, C., Ukegbu, A., Ilikannu, S., Ibeh, C., Onyeonoro, U., and Ezeanyim, A., 2015). In order to inspire positive health behaviour and reduce the burden of cervical cancer in Nigeria, and other countries, National Cancer Prevention Programme (NCPP), and several other non- governmental organizations in Nigeria and the world all over, such as (Stand Up To Cancer Nigeria), Jo's Trust Foundation a non- governmental organization based in United Kingdom and National Cervical Cancer Coalition based in United States of America among others have utilized and continue to utilize the internet as a medium for cervical cancer awareness creation using various posters (www.jostrust.org.uk; www.standuptocancer.com). The essence is to sensitize women to adopt healthy anti cervical cancer behaviours and to seek early medical advice when it occurs. It is pertinent to note that in Nigeria, the National Cancer Prevention Programme (NCPP), and other organizations whose mission is to reduce the burden of cervical cancer have contributed to a $15 \%$ reduction of cervical cancer deaths in Nigeria, from 26 women dying daily in 2008 to 22 in 2012 (WHO 2015).

However, the number of women dying daily is still on the high side. Ginsberg, Lauer, Zelle, Baeten, and Baltssen, (2012) and Njoroge and Mberia, (2014) aver that prevention remains the cornerstone in the fight against cervical cancer worldwide. Although some prevention methods have been proposed, many remain inaccessible to women in developing countries who ironically, given the limited diagnostic and curative facilities available to them, need prevention the most. Cervical cancer is a public health concern for which screening is a forefront prevention strategy; however, screening rate remains low (Idowu, Olowookere, Fagbemi and Ogunlaja, 2016). In order to motivate people to change unhealthy habits and adopt healthy lifestyles, health educators quite often resort to the use of fear appeals by presenting people with information that stresses on individual's vulnerability to a health risk, the severity of this risk, or both. Fear appeals also hope to raise motivation to carry out a protective behavior by raising individual's efficacy of the response (Witte, 1992). Hence, judging from the strength of fear appeal in motivating people to adopting healthy behaviour, it is hoped that if on-line cervical cancer awareness posters promote threatening health information on cervical cancer as well as provide effective and clear recommendation on how to avert cervical cancer, the seemingly increase of cervical cancer would be reduced. The essence of this study therefore, is to content analyze on-line posters on cervical cancer awareness.

\section{Statement of the Problem}

The above background clearly shows that cervical cancer related deaths in the world in general and Nigeria in particular are on the increase (WHO, 2015), perhaps this explains why World Health Organization declares January of every year as cervical cancer awareness month. The latest world health report shows that at least 22 women die daily due to cervical cancer (WHO, 2015). Though there have been series of awareness aimed at promoting health behaviours capable of ameliorating the 
incidence of cervical cancer related deaths, the situation has maintained steady increase (Tran, Choe, Taylor, and Ko, 2011). Research evidence showed that in spite of the huge resources, energy and time invested on the series of awareness creation only insignificant five percent compliance was recorded (WHO, 2015). The reason for the low compliance to safety measures by the message and or campaign targets is yet to be ascertained empirically especially from communication prism. The research therefore, seeks to investigate whether this problem is attributed to the nature of the messages (i.e., how it was articulated). The researchers consider this a major gap in knowledge and practice which this study hoped to fill. It is, therefore, germane to examine the cervical cancer awareness posters using Extended Parallel Processing Model to describe the content structure of online posters on cervical cancer awareness messages.

\subsection{Research Questions}

1. What level of threat is played up in the on-line posters under study?

2. What is the dominant pattern of efficacy in the on-line poster messages?

In view of the awareness/information on cervical cancer being carried out in Nigeria, it would be assumed that the death recorded on cervical cancer would be minimal. On the contrary however, the nation has witnessed prevalence of cervical cancer deaths despite the enlightenment campaigns/information. It is hoped that this study would provide significant insights on the content of the message used for awareness. The outcome of the study, it is further hoped, will contribute in guiding the policy makers, in making a positive decision that will benefit the target beneficiary.

\subsection{Theoretical Framework}

The EPPM is a framework developed by Kim Witte in 1992. The EPPM is based on the explanatory mechanism of Leventhal's (1970, and 1971) Protection Motivation Theory (PMT) with Roger's (1975 and 1980) PVT research focusing on what makes fear appeals work. The important components of fear appeal process are; Fear, Threat, Efficacy and Outcome. The EPPM proposes that threat initiates and motivates message processing because the greater the threat, the greater the fear aroused, the more attention getting the message (through depictions of the significance of the severity), and the more involving the message (through depictions of susceptibility). Several scholars like, Johnson and Eagly, 1989; Petty and Cacioppo, 1986, have noted the crucial role of involvement in persuasion, as when perceptions of threat are low, then people are not motivated to continue message processing, because the threat is perceived as either irrelevant or trivial. Fear appeal messages have been useful in behavior change as they highlight the risk(s) an individual faces for performing or not performing a recommended action. In the case of cervical cancer, women face significant risks if diagnosed of cervical cancer which leads to death (Stephenson \& Witte, 1998). Specifically, the EPPM utilizes the protection motivation theory linkages among perceived levels of severity, susceptibility, response efficacy, and self-efficacy that lead to message acceptance and, ultimately, attitude, intention and behavior changes. The EPPM suggests that when presented with a risk message, individuals engage in two appraisal processes which produce one of three outcomes:

First, individuals appraise whether they are susceptible to the identified threat and whether the threat is severe. Perceived susceptibility is the extent to which an individual feels at risk for a particular health threat, whereas perceived severity is the extent to which an individual believes the threat to be serious or harmful. If the threat is perceived as either trivial or irrelevant, they will ignore the risk message and not even think about recommended behaviors (because they feel the threat is not of concern to them).

Second, if individuals believe they are susceptible to a severe threat (i.e., high perceived threat, which comprises both perceived susceptibility and perceived severity) and fear is aroused, they are motivated to act and appraise the extent to which the recommended response effectively deters the threat (i.e., response efficacy) and the extent to which they are able to perform the recommended response (i.e., self-efficacy). When perceived threat is high and individuals believe themselves able to perform a recommended response that effectively minimizes the threat, they will control the danger and follow the recommended guidelines. However, when the perceived threat is high but individuals doubt their ability to effectively minimize the threat (such as personal, social or physical barriers), they turn instead to controlling their fear and engage in denial, or defensive avoidance. 
In sum, perceived threat (i.e., perceived susceptibility and severity) motivates action. Perceived efficacy (i.e., recommended response efficacy and self-efficacy) determines whether individuals control the danger and make behavioral changes or control their fear through psychological defense mechanisms, such as defensive avoidance or reactance (rejection of message). According to the EPPM, women who perceive cervical cancer disease to be a significant health threat and believe that going for screening for early detection is effective are more likely to make a cognitive choice to engage in protective health behaviors (i.e., danger control). In contrast, women who are afraid to attend cervical cancer screening or think that screening tests are not necessary are likely to focus on their emotional response. These individuals are likely to ignore or react to the advocated message leading to continued cervical cancer screening services disuse (i.e., fear control).Overall, the EPPM claims that perceived efficacy determines whether danger control accesses or fear control processes are initiated, and perceived threat determine the intensity of these responses. Danger control processes are primarily cognition processes where individuals evaluate their susceptibility to the threat, the severity of the threat, their ability to perform the recommended response (perceived self-efficacy), and the effectiveness of the recommended response (perceived response efficacy).

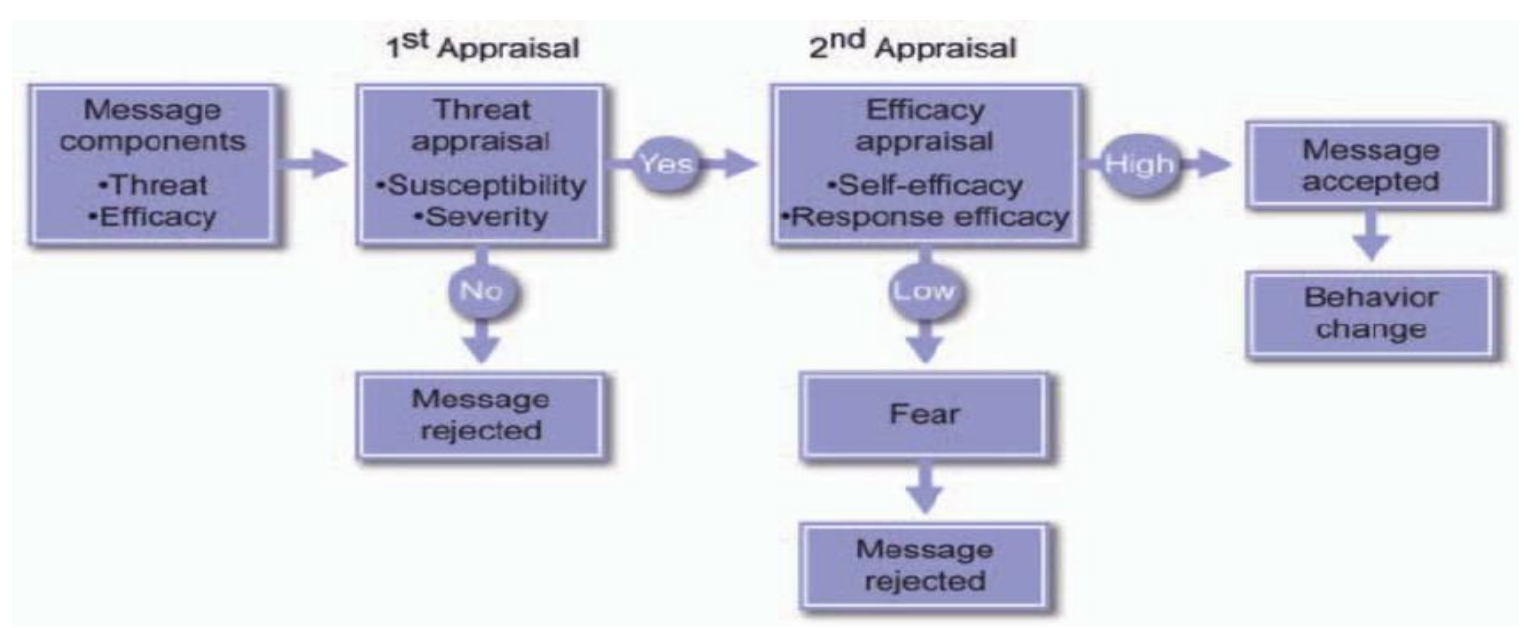

Fig1. Extended Parallel Processing Model (Source: Adapted from Witte, 1992).

\section{LiTERATURE REVIEW}

In an empirical study by El-Toukhy, Holman and Gibson (2017) on exemplifying risk: effects of health exemplars and risk prevalence on perceived susceptibility, severity and vaccination intentions, which was carried out in the United State of America, the purpose of the study was to examine whether perceived susceptibility, severity and vaccination intentions differed as a function of exemplar type and vaccination intentions. The method of study was survey and sampling technique employed was convenience. Participants first completed demographics and covariates questions; read one news story that appeared on a faux health website; and completed measure of perceived susceptibility, severity and vaccination intentions. They found that participants exposed to recovery exemplars had higher perceived severity than did those to no exemplars. Also, participants exposed to a high-prevalence risk story had higher perceived susceptibility but lower perceived severity than those exposed to a low-prevalence risk story. Exposure to recovery exemplars led to increased perceived severity, which increased perceived susceptibility, leading to increased influenza vaccination intentions.

In Germany, Hansen, Eisnera, Pfallerb, and Schicktanza (2017), conducted a study on "Are You In or Are You Out?!" Moral Appeals to the Public in Organ Donation Poster Campaigns: A Multimodal and Ethical Analysis. They developed a detailed multimodal approach for the analysis of health communication by focusing exemplarily on such organ donation poster campaigns as a common mean since the 1990s. They identified 13 campaigns with 83 posters from 1996 to 2016 . They focused on both the textual and visual elements of such material to analyze how morally relevant principles and virtues are interwoven. Six categories of moral appeals were identified in the complete sample. In the United States of America, a comparative study by Primack, Carroll, Shensa, Davis and Levine (2016), examined sex differences in Hookah-Related images posted on Tumblr. They adopted content analysis as their method of study and they used a systematic process involving stratification by time 
of day, day of week, and search term to gather a sample of 140 Tumblr posts related to hookah tobacco smoking. They found that $77 \%$ of posts were posted by females and $35 \%$ were posted by individuals younger than 18 . The most prominent features displayed in all posts were references to or images of hookahs themselves, sexuality, socializing, alcohol, hookah smoke, and tricks performed with hookah smoke.

Also, in an empirical study by Griffin (2015), on posters for public: WAP posters and national dialogue about health care in the United States. The study was carried out in the United States of America and the purpose of the study was to explore the role of Works Project Administration (WAP) public health posters in Depressing USA. Another purpose of the study was to outline clear source of threat as well as clear methods of resolution. The method of study was both quantitative and qualitative research in analyzing the visual messaging strategies employed by WAP poster artists when discussing public health. One of the study's content categories was visual cues. The use of English language is an exclusionary representational choice, irrespective of the large international population specifies the intended audience (and in this case, the English speaking white people) of the poster. He found that the posters pictures show clear sources of threat and clear strategies for resolution.

Tannenbaun, Helper, Zimmerman, Saul, Jacobs, Wilson and Albarracin (2015) in a comprehensive meta-analysis investigating fear appeals' effectiveness for influencing attitude, intention, and behaviours, tested predictions from a large number of theories, the majority of which have never been tested meta-analytically until now. Studies were included if they contained a treatment group exposed to a fear appeal, a valid comparison group, a manipulation of depicted fear, a measure of attitudes, intentions, or behaviors concerning the targeted risk or recommended solution, and adequate statistics to calculate effect sizes. The meta-analysis included 127 articles (9\% unpublished) yielding 248 independent samples $(N$ Total_ 27,372) collected from diverse populations. Results showed a positive effect of fear appeals on attitudes, intentions, and behaviors, with the average effect on a composite index being random-effects $d_{-}-0.29$. Moderation analyses based on prominent fear appeal theories showed that the effectiveness of fear appeals increased when the message included efficacy statements, depicted high susceptibility and severity, recommended one-time only (vs. repeated) behaviors, and targeted audiences that included a larger percentage of female message recipients. Overall, they concluded that fear appeals are effective at positively influencing attitude, intentions, and behaviors. Similarly, in an earlier study conducted by Stephenson and Witte (1993) titled 'Fear, Threat, and Perceptions of Efficacy from Frightening Skin Cancer Messages' fear appeal messages were designed and tested to ascertain their effectiveness in promoting skin protective behaviors. Theoretically guided by the Extended Parallel Process Model, the fear appeal messages in this study conveyed the seriousness of exposed and unprotected skin for college students in the Southwestern United States, and recommended a series of behaviors that would protect individuals from serious sunburns. The results demonstrated that fear appeals are effective in promoting skin protective behaviors. Specifically, highly threatening fear appeal messages were most effective when combined with a strong efficacy message emphasizing the effectiveness of the recommended behavior.

Allen and Witte (2000) conducted a Meta-Analysis of Fear Appeals: Implications for Effective Public Health Campaigns. The fear appeal literature was examined in a comprehensive synthesis using metaanalytical techniques. The meta-analysis suggests that strong fear appeals produce high levels of perceived severity and susceptibility, and are more persuasive than low or weak fear appeals. The results also indicate that fear appeals motivate adaptive danger control actions such as message acceptance and maladaptive fear control actions such as defensive avoidance or reactance. It appears that strong fear appeals and high-efficacy messages produce the greatest behavior change, whereas strong fear appeals with low-efficacy messages produce the greatest levels of defensive responses. In a laboratory experimental study on Examining HPV Threat-to-Efficacy Ratios in the Extended Parallel Process Model conducted by Carcioppolo, Jensen, Wilson, Collins, Carrion, and Linnemeier, (2013), women $(n=442)$ were exposed to human papilloma virus (HPV) prevention messages containing one of six threat-to-efficacy ratios and one of two message frames (messages emphasizing the connection between HPV and cervical cancer or HPV and genital warts). Multiple mediation analysis revealed that a 1-to-1 ratio of threat to efficacy was most effective at increasing prevention intentions, primarily because it caused more fear and risk susceptibility than other message ratios. Response efficacy significantly mediated the relationship between message framing and intentions, 
such that participants exposed to a genital warts message reported significantly higher intentions, and this association can be explained in part through response efficacy.

Also, in an earlier observational study conducted by Green and Witte (2006) on can fear arousal in public health campaigns contribute to the decline of HIV prevalence? The authors provided overviews of the prevailing American expert view, African national views, and the findings on the use of fear arousal in behaviour change campaigns. Their analysis suggests that American post-sexual revolution values and beliefs may underlie rejection of fear arousal strategies, whereas a pragmatic realism based on personal experience underlies Africans' acceptance of and use of the same strategies in AIDS prevention campaign. There is evidence that fear-motivated behavior changes actually occurred in American gay community's hard hit by AIDS, leading to sharp declines in HIV infections in the mid1980s, even before most formal AIDS prevention programs were launched. That is, firsthand experience with sick and dying partners and friends led to fear of contracting AIDS, and it seems to have been this rather than formal public health interventions that led to reductions in behaviors that exposed men to HIV infections (Judson,1983; Stoneburner and Low-Beer, 2004).

Another study conducted in Nairobi by Njoroge and Mberia (2014) on fear arousing persuasive communication: the use of threat and coping appraisal in breast cancer messages, used content analysis as their research method to examine print media articles. They employed a direct content analysis where categories and codes were developed on theory. Samples were purposively selected. They found that with levels of high threat and coping appraisal low in the print media messages, it is unlikely that the messages will motivate breast self examination.

Gjalt-Jorn Y. P, Robert, A.C. Ruiter and Gerjo K. (2013) in a meta-analysis study on Threatening communication: a critical re-analysis and a revised meta-analytic test of fear appeal theory found that there was a significant interaction between threat and efficacy, such that threat only had an effect under high efficacy (d_0.31), and efficacy only had an effect under high threat (d_0.71). A somewhat worrying finding of this meta-analysis was that under low efficacy, the effect of threat was negative and almost significant. This is in line with the terror management health model (Goldenberg and Arndt, 2008), which suggests that threatening information can cause people to engage in healthdefeating behaviour. If future research confirms this association, that would render the use of threatening information very risky. If an intervention developer is not very certain that either the population is high in response and self-efficacy, or that a given relevant intervention will manage to considerably increase response and self-efficacy, threatening communications should be avoided (in fact, the significant main effect of efficacy and the strong effect of efficacy under high threat that were found in the current meta-analysis suggest that a focus on efficacy is a better bet in any case). They concluded that, warning labels on packs of cigarettes seem ill-advised as they may in fact increase smoking among smokers who derive self-esteem from their identity as a smoker. They recommended that more health benefits would be achieved if the areas currently reserved for warning labels would be used for a message to enhance efficacy or influence other determinants that have been found to play a role in ceasing smoking (such as subjective norm; note that attitude, the construct encompassing perceived threat, has been found to have only a weak influence; Topa and Moriano, 2010). Given the minimal, or even negative, effects we can expect from threatening communication, the potential of evidence- and theory-based communications on cigarette pack labels is promising.

In a qualitative study titled 'Scared straight? Fear-appeal anti-smoking campaigns, risk, self efficacy and addiction, conducted by Thompson, Barnett, and Pearce (2009) based on a qualitative study in Christchurch, New Zealand, this research aimed to investigate the ways that people respond to antismoking campaigns and to raise concerns about the ways that fear-appeal campaigns in particular may serve to reinforce the stigmatization of 'hard-core' smokers. Generally, campaigns have been effective and behaviour change has occurred in groups and individuals who have high levels of self-efficacy. In an earlier study exploring reasons for the success and failure of health campaigns, the authors found that campaigns addressing only efficacy may be more likely to fail and that in order to act, individual must first feel threatened (Witte, Berkowitz, Cameron and Mckeon, 1998). Another study looked at two different types of messages, high threat/no efficacy and high efficacy/no threat, finding showed that messages that contained only an efficacy component were more effective among participants who previously reported high levels of fear (Gore and Bracker, 2005). 


\section{Methodology}

The nature of the study therefore, requires the researchers to study existing communication contents in addition to sourcing information from the respondents in their natural settings. Therefore, the researchers used Content analytical research method to analyze online posters on cervical cancer. The study content analyzed on-line posters on cervical cancer awareness. In view of this, the scope of the study involves looking through the lens of Extended Parallel Processing Model, where the key themes to be analyzed were derived to ascertain, via content analysis, and how posters under study covered the identified content categories. Precisely, content analysis was used to evaluate online posters on cervical cancer awareness.

\subsection{Population of Study}

Millions of on-line cervical cancer awareness posters abound in the internet. Since trying to get the exact number of posters that abound can be 'a daunting task' (Wimmer and Dominick, 2011), the researchers decided to make use of the first one thousand different posters that appeared in the Google search engine as the population for the content analysis. Wimmer and Dominick (2011) offer a justification where they submit that a researcher can work with the acceptable listing of the manifest content of interest found in the web. It is pertinent to note that the plethora of the posters found were evenly spread across the globe and are therefore; replete with necessary information required for greater enlightenment about cervical cancer. However, the actual population for the study was the 26 posters which have Nigerian sources indicating that the posters emanate from Nigeria. The population is considered not too large for the researchers to manage as such census method was used. This is instructive considering the consensus among experts that when a population is too small to be sampled, census becomes imperative (Nwodu, 2017; and Wimmer and Dominick, 2011).

\subsection{Units Of Analysis}

Below are the manifest contents to be examined in the posters under study and their corresponding attribute or content categories:

(i) Style of message presentation- This was measured in terms of how the message was presented. This was categorized into:

(a) Only letters

(b) Pictorials only

(c) Pictorial/letters

(ii) Tone of message- this was categorized into:

(a) Severe

(b) Mild

(c) Neutral

(iii) Perceived Threat- the indicators were:

(a) Caution

(b) Threat to life

(c) Death

(d) All women regardless of race

(e) Multiple sex partners

(f) Pre-marital sex

(g) Risk factors (Obesity/Smoking)

(iv) Perceived Efficacy- the indicators were:

(a) Screening (Preventive)

(b) Treatment (Curative)

(c) Give step by step instructions to avert the threat 
(d) Give contact address for further inquiry

(e) Promote self confidence

(f) Provide information about cervical cancer/treatment/equipment

(g) Show skills in their achievement effort to prevent cervical cancer

\subsection{Coding Instructions and Guides}

Two coders were trained thoroughly to acquaint them with the research objectives, operational definitions of key concepts, code items, coding guide and styles, and other details that would equip them to carry out a highly efficient, meticulous and systematic coding with very minimal error.

\section{Data ANAlysis AND Results}

The essence of the study was to textually evaluate how Nigerian online poster messages promoted threat and efficacy in their cervical cancer awareness messages. Therefore, the 26 posters which have Nigerian sources indicating that they emanate from Nigeria were content analyzed. Data obtained from the study were presented in the tables below.

Table1. Analysis of Style of message presentation

\begin{tabular}{|c|c|c|}
\hline & Frequency & Percentage \\
\hline \multirow{3}{*}{\begin{tabular}{|l|} 
only letters \\
pictorials/letters \\
only pictorials \\
Total \\
\end{tabular}} & 8 & 30.8 \\
\hline & $\begin{array}{l}18 \\
- \\
\end{array}$ & 69.2 \\
\hline & 26 & 100.0 \\
\hline
\end{tabular}

Source: 2019 Content Analysis

Data contained in Table 1 above shows that out of the 26 on-line posters on cervical cancer studied, $69.2 \%$ of the posters presented the message on cervical cancer in both pictorials and letters, while $30.8 \%$ used only letters to present messages on cervical cancer.

Also, table 2 below shows data obtained in respect of the tone of the message presentation.

Table2. Analysis of Tone of message

\begin{tabular}{|l|l|l|}
\hline & Frequency & Percentage \\
\hline \multirow{2}{*}{$\begin{array}{l}\text { severe } \\
\text { mild }\end{array}$} & 6 & 23.1 \\
\cline { 2 - 3 } Toutral & 18 & 69.2 \\
\cline { 2 - 3 } & 2 & 7.7 \\
\cline { 2 - 3 } & 26 & 100.0 \\
\hline
\end{tabular}

Source: 2019 Content Analysis

The above Table 2 shows that out of the 26 posters studied, 18 representing $69.2 \%$ used mild tone in their message presentation; 6 representing $23.1 \%$ used severe tone in their message presentation while 2 representing $7.7 \%$ were neutral in their tone of message.

Research Question one: What level of threat is played up in the on-line posters under study?

It was found that $57.9 \%$ of the messages on cervical cancer used caution; $45.3 \%$ presented message on cervical cancer to be threat to life; $15.3 \%$ of the online poster messages on cervical cancer presented cervical cancer as deadly; while $21.1 \%$ of the messages played up multiple sex partners as making one to be susceptible to cervical cancer.

Research Question two: What is the dominant pattern of efficacy in the on-line posters messages?

The answer to the above clearly shows screening as the dominant pattern of efficacy in the online poster messages. Thus, $47.7 \%$ of the on-line poster on cervical cancer messages show screening as the most dominant pattern of efficacy; 5 representing $33.3 \%$ of the on-line poster messages provided contact address for further inquiry as the second most dominant pattern of efficacy. $13.3 \%$ of the messages also promoted self confidence as efficacy. However, the poster messages did not provide any information on efficacy regarding; treatment; showing skills in their achievement effort to prevent cervical cancer; and providing information about cervical cancer/treatment and equipment. 


\subsection{Discussion of Findings}

The content analysis sought to examine the on-line posters on cervical cancer messages through the lens of the Extended Parallel Processing Model (EPPM), and to describe the content structure of the awareness messages on cervical cancer. The two major factors of EPPM (threat and efficacy) served as the main coding categories to assess the posters' potential persuasiveness. At least two studies have demonstrated with factor analyses that severity and susceptibility are separate dimensions that combine to compose a higher order factor of threat, and that response efficacy and self-efficacy are separate dimensions that combine to compose a higher order factor of efficacy (Witte, Cameron, McKeon and Berkowitz, 1996). Therefore, the posters were analyzed only if they used at least one type of threat (i.e., susceptibility and/or severity) and one type of efficacy (i.e., self efficacy and/or response efficacy).

The finding revealed that out of the 26 posters studied, 19 posters employed threat, as $57.9 \%$ of the messages on online posters employed cautious healthy behaviour practices, followed in descending order by threat to life, death, and multiple sex partners. From the result therefore, it was obvious that on-line posters on cervical cancer played up minimal threat fear appeals. Thus, data obtained, show that online poster messages on cervical cancer soft-peddled the message about the severity of cervical cancer. This is so because a majority of the on-line poster messages do not contain much on fear arousal which motivates action. This is also evident in the tone used in the message presentations, where $69.2 \%$ of the messages were written in mild tones while only $23.1 \%$ of the messages were severe in their tone of message presentation. This finding is consistent with the Extended Parallel Processing Model (Witte, 1992) that fear appeal literature in totality suggests that fear-arousing messages reliably and consistently produce behaviour change. Based on this finding one could conclude that threats were not commonly employed in the on-line posters studied.

The implication of this finding is that minimal threat fear appeals appear to produce little or no persuasive effects. The EPPM, theory predicts no behaviour change when a threat is not severe, one is not susceptible to it, and there is no effective response. Thus, online posters on cervical cancer should play up high level of threat and greater level of efficacy to promote behaviour change. Also, Tannenbaum et al, (2015) reaffirm this, when they found in their study that fear appeals with high depicted severity and high depicted susceptibility will positively influence attitude, behaviour and intention. For instance, Uganda's earliest AIDS posters used imagery of human skulls, coffin and grim reapers harvesting humans. This strategy motivated behavioural change which led to an approximately 66\% decline in HIV prevalence in Uganda (Shelton at al 2002).

However, when fear-associated approaches initially favoured and indeed developed by African governments eventually were replaced by the softer, gentler approach favoured by American AIDS experts, after roughly in the mid 90s, there were indications of a possible increase in HIV rates in Uganda (Green and Witte, 2006). This finding reinforces the finding of El-Toukhy, Holman and Gibson (2017) that exposure to recovery exemplars led to increased perceived severity, which increased perceived susceptibility, which led to influenza vaccinations intentions. The finding also corroborates the finding of Griffin (2015) that posters for public health in USA show clear sources of threat and clear sources of strategies for resolution unlike what obtained in the Nigerian posters which portrayed minimal threat.

It, therefore, behooves that more effort should be made to stress individuals' susceptibility to cervical cancer and the severity of cervical cancer. This can be achieved through the use of vivid language and pictures that describe the terrible consequences of a health threat to increase perceptions of severity of threat. Also, personal language (e.g., "You face a 30\% chance of experiencing the threat") that emphasizes the similarities between victims of a health threat and the target audience should be employed in the message as that would increase women's perceptions of susceptibility.

An evaluation of the dominant pattern of efficacy in the on-line posters on cervical cancer awareness messages showed screening as the most dominant pattern of efficacy. This finding shows that efficacy messages $(n=15)$ are very minimal in the online posters on cervical cancer when compared with the total number of level of threat messages played up $(=19)$. The import of this finding is that the level of threat played up significantly outweighs the efficacy employed in the online posters and the implication according to the theory of EPPM, is that the persuasive messages in the posters could backfire as a result of the imbalance between the perceived threat and perceived efficacy. This finding 
not only validates the outcome of an earlier finding by Gjalt-Jorn, Robert, Ruiter and Gerjo (2013) which established that when threat is increased but efficacy is low, defensive reactions are predicted, such as denying the severity of or susceptibility to the threat. This finding also reinforces earlier research findings which revealed that with levels of high threat and coping appraisal low in the print media messages it is unlikely that the messages will motivate breast self examination (Njoroge and Mberia's, 2014; and Griffin, 2015).

Most of the posters studied have only screening as their efficacy recommendation. However, with a one-line recommendation, the online poster messages run the risk of backfiring, since they may produce defensive responses in people with low-efficacy perceptions. Fortunately, practitioners can easily make their fear appeals effective by providing high-efficacy messages. As such, health communicators should feature recovery exemplars in the online posters on cervical cancer, for their effectiveness in triggering perceived efficacy (causing hope) which will promote behavioural change. To this, El-Toukhy, Holman and Gibson found that exposure to recovery exemplars led to increased perceived severity, which increased perceived susceptibility, as well as increased influenza vaccination intention. Impliedly, information needed to avert cervical cancer was not easily and effectively provided in the online posters. The inclusion of efficacy statements in fear appeal will lead to increased effectiveness (Tannenbaum et al, 2015; Helper, Zimmerman, Saul, Jacobs, Wilson and Albarracin, 2015 and Green and Witte, 2006). In sum, the online posters messages on cervical cancer will be more effective when they depict a significant and relevant threat (to increase perceptions of severity and susceptibility) as well as outline effective responses that are easy to accomplish (to increase perceptions of response efficacy and self efficacy).

\section{CONCLUSION AND RECOMMENDATIONS}

Based on the data gathered and analyzed above, it is obvious among other things that:

1. The level of threat played up in the online poster messages on cervical cancer was low. This means that threats were not commonly employed in the on-line posters studied.

2. The dominant pattern of efficacy used in the online posters was screening (which is response efficacy), however, the online poster messages on cervical cancer were silent on self efficacy (i.e. the ability that one could actually follow the recommended response to avert cervical cancer).

In view of the above, the researchers made the following recommendations:

1. Development and health communication practitioners can develop effective fear appeal messages by increasing references to the severity of the threat (i.e., the magnitude of harm) and references to the target population's susceptibility to the threat (i.e., their likelihood of experiencing the threat), since it was found that there was perceived low threat.

2. It was also recommended that efficacy messages should be designed in such a manner that would persuade the target population to believe that they are able to perform a recommended response (i.e., strong self-efficacy perceptions) and that recommended responses work in averting or minimizing a threat (i.e., strong response efficacy perceptions), since it was found that efficacy messages were scarce in the online posters on cervical cancer studied.

3. Development and health communication practitioners should always ensure that a high-threat fear appeal is accompanied by an equally high-efficacy (or greater) message (given the findings that low-efficacy messages produce greater fear control responses). Messages should always be carefully pretested to ensure they are producing high-threat and, more important, high-efficacy perceptions.

4. Future researchers should evaluate foreign on-line poster messages on cervical cancer with a view to determine whether they contained high threat and high efficacy found to be lacking in the posters studied.

\subsection{Contribution to Knowledge}

Strengthened by these findings, the researchers developed a 'high threat-high efficacy message acceptability model' which the researcher considered a major contribution to the knowledge and practice of health communication.

The model is illustrated below: 


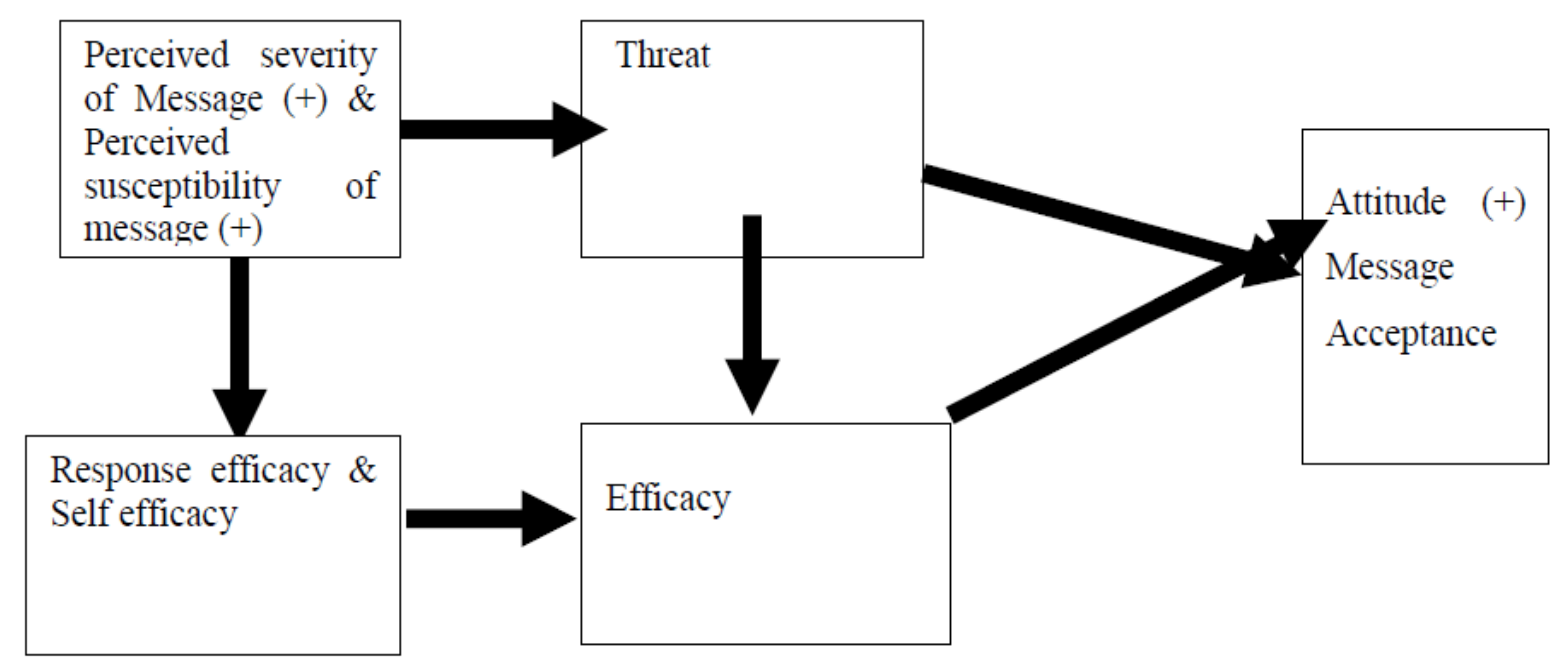

Fig2. High Threat-High Efficacy Message Acceptability Model

The model is self-explanatory. It derives from the outcome of this study and tends to explain what could make online poster messages on cervical cancer to either succeed or fail in its advocacy. The model shows that if people appraise the health advocacy messages to be harmful (perceived severity) and feel at risk that they may fall victim of the threat (perceived susceptibility), combined with their high perceived efficacy (i.e. response efficacy and self-efficacy) which is their ability that they can perform the recommended action and are able to actually perform the recommended action i.e. go for screening which is the acceptability of the message, will influence the outcome, which is attitude change. In other words, if they appraise the poster messages to be trivial, it will lead to message rejection. However, if they perceive the severity in the poster messages to be high, perceive the response efficacy to be high as well but have low self efficacy, the outcome will be message rejection too. The import, therefore, is that most online poster massages on cervical cancer failed to achieve its objective because the messages or campaigns were not embedded with the components of fear appeals that encourage positive attitude which will lead to adoption. The researchers, therefore, consider this as a modest contribution to knowledge which requires further studies for proper crystallization, clarification and possible validation.

\section{REFERENCES}

[1] Afri-Dev, I. (2014). Intergrated Africa Cancer Factsheet Focusing on Cervical Cancer. Girls and Women Health/Sexual \& Reproductive Health, HIV \& Maternal Health .

[2] Allen, M., and Witte, K., (2000) conducted a Meta-Analysis of Fear Appeals: Implications for Effective Public Health Campaigns. Health Education \& Behavior, Vol. 27 (5): 591 -615.

[3] Chia, N.C., Udzua, F.K., \& Ugese, J.I., (2016) Assessment of Knowledge of Cervical Cancer and Pap Smear Screening in Makurdi Metropolis. Journal of Health Science 4, 283-289 doi: 10.17265/23287136/2016.06.001.

[4] Dillard, J. P., Plotnick, C. A., Godbold, L. C., Freimuth, V. S., \& Edgar, T. (1996). The multiple affective outcomes of AIDS PSAs: Fear appeals do more than scare people. Communication Research, 23, 44-72. http://dx doi.org/10.1177/009365096023001002

[5] Fraenkel, J,R., \& Wallen, N.E. (2007). How to Design and Evaluate Research in Education. New York: McGraw-Hill.

[6] Griffin, D. (2015). Posters for public health: WAP posters and national dialogues about health care in the united States. Communication Design, 3:2, 124-141.

[7] Hansen, S.L., Eisner, M.I., Pfaller, L., \& Schicktanz (2017). ”Are You In or Are You Out?!” Moral Appeals to the Public in Organ Donation Poster Campaigns: A Multimodal and Ethical Analysis. Health Communication, 21:3, 366-375.

[8] Idowu, A., Olowookere, S.A., Fagbemi, A.T., \&Ogunlaja O.A., (2016). Determinants of cervica cancer screening uptake among women in Ilorin, north central Nigeria: a community-basedstudy. Journal of cancer epidemiology volume 2016 (2016), article ID 6469240, 8 pages. http://dx.doi.org/10.1155/201 6/6469240. Assessed on 15/6/2016

[9] Jedy-Agba, E., Curado, M.P., Ogunbiyi, O., et al (2012). Cancer incidence in Nigeria: a report from population-based cancer registries. Cancer Epidemiol; 36: e271-8. http://dx.doi.org/10.1016/j.canep.2012. 04. 007Assessed on 15/6/2016 
[10] Leventhal H., (1970). Findings and theory in the study of fear communication, in Berkowitz L (ed.): Advances in Experimental Social Psychology.NewYork: Academic Press, pp. 119- 186.

[11] Leventhal, H., (1971). Fear appeals and persuasion: The differentiation of a motivational construct. AmJ Public Health 61:1208-1224.

[12] Leventhal, H., Safer M.A., Panagis, .M. D, (1983).The impact of communications on the self-regulation of health beliefs, decisions, and behavior.Health Education Quarterly 10:3- 29.

[13] Morman, M. (2000). The influence of fear appeals, message design, and masculinity on men's motivation to perform the testicular self-exam. Journal of Applied Communication Research, 28, 91-116.

[14] Ndikom, C.M., \&Ofi, B.A. (2012).“Awareness, perception and factors affecting utilization of cervical cancer screening services among women in Ibadan, Nigeria: a qualitative study," Reproductive Health vol. 9, artcle 11 .

[15] Njoroge, K.S. \& Mberia, H. (2014). Fear Arousing Persuasive Communication: Threat and Coping Appraisal in Breast Cancer Messages. International Journal Academic Research in Business and Social Science. Vol.4, No.10

[16] Noar, S.M. (2006). A 10-Year Retrospective of Research in Health Mass Media Campaigns: Where Do We Go From Here?. Journal of Health Communication, 11(1), 21-42. Retrieved 4 November, 2017, from http://dx.doi.org/10.1080/10810730500461059

[17] Nwodu, L.C. (2017). Research in communication and other behaviourial sciences. Enugu: RhyceeKerex Publishers.

[18] Noar, S.M. (2006). A 10-Year Retrospective of Research in Health Mass Media Campaigns: Where Do We Go From Here? Journal of Health Communication, 11(1), 21-42. Retrieved 4 November, 2017, from http://dx.doi.org/10.1080/10810730500461059.

[19] Primack, B.A., Carroll, M.V., Shensa, A. Davis, W. \& Levine, M.O.(2016). Sex Differences in HookahRelated Images Posted on Tumbir: A Content Analysis. Journal of Health Communication, $\quad 21: 3, \quad 366-$ 375.

[20] Ruiter, R.A.C, Abraham, C, \& Kok, G. (2004). Scary warnings and rational precautions: A review of the psychology of fear appeals. Psychology and Health, 16, 613-630.

[21] Smalec, J. L. \& Klingle, R. S. (2000). Bulimia interventions via interpersonal influence: The role of threat and efficacy in persuading bulimics to seek help. Journal of Behavioral Medicine, 23(1), 37-57.

[22] Stephenson M., Witte, K., (1998).Fear, threat, and perceptions of efficacy from frightening skin cancer messages.Public Health Rev 26:147-174.

[23] Tannenbaun, Helper Zimmerman, Jacobs, Wilson \& Albarracin (2015). Appealing to Fear: A MetaAnalysis of Fear Appeal Effectiveness and Theories. American Psychological Association Vol. 141, No. 6, 1178-1204 0033-2909/15/\$12.00 http://dx.doi.org/10.1037/a0039729.

[24] Thompson, L.E., Barnett, J.R. and Pearce J.R. (2009). 'Scared straight? Fear-appeal anti-smoking campaigns, risk, self efficacy and addiction'. Health, Risk \& Society. Vol. 11, No. 2, April 181-196

[25] Tran, N.T., Choe, S.I, Taylor, R., Ko, W.S., (2011). Knowledge, Attitude and Practice (KAP) Concerning Cervical Cancer and Screening among Rural and Urban Women in Six Provinces of the Democratic People's Republic of Korea. Asian Pacific Journal of Cancer Prevention. Vol 2. Assessed on $13^{\text {th }}$ June, 2015

[26] Witte, K. (1992). Putting the fear back into fear appeals: The extended parallel process model.

[27] Witte, K., (1998). Fear as motivator, fear as inhibitor: Using the extended parallel process model to explain fear appeal successes and failures, in Andersen PA and Guerrero LK (eds): Communication and Emotion: Theory, Research, and Applications. San Diego, CA: Academic Press, pp. 423-450.

[28] Witte, K., Berkowitz, J., McKeon, J., Cameron, K., Lapinski, M.K., \& Liu, W.Y. (1996). Radon Awareness and Reduction Campaigns for African-Americans: A Theoretically-Based Formative and Summative Evaluation. Paper presented at the annual meeting of the Speech Communication Association, San Diego, California.

[29] Witte, K. \& Allen, M. (2000). A Meta-Analysis of Fear Appeals: Implications for Effective Public Health Campaigns. Health Education \& Behavior, Vol. 27 (5): 591-615.

[30] World Health Organization, Cervical cancer, world health organization, Geneva, Switzerland, 2015,http://www.afr..who.int/en/clusters-a-programmes/dpc/non-communicable-disease managementndm /programme-components/cancer/cervical-cancer/2810-cervical- cancer.html. Assessed on 15/6/2019

[31] World Health Organization, (2015, June 15). www.who.int/mediacentre/factsheets/fs29n. Retrieved February 15, 2019, from www, who.int/mediacentre/factsheets/fs29n.

[32] World Health Organization, (2002). The world health report 2002. Reducing risks, promoting healthy life. Geneva: Author. 
[33] World Health Organization, (2003). Diet, nutrition and the prevention of chronic diseases. Geneva: Author.

[34] World Health Organization, Cervical cancer, world health organization, Geneva, Switzerland, 2015,http://www.afr..who.int/en/clusters-a-programmes/dpc/non-communicable-disease managementndm /programme-components/cancer/cervical-cancer/2810-cervical- cancer.html. Assessed on 15/6/2019

[35] www.anambramwa.org. Assessed on $29^{\text {th }}$ June, 2019.

Citation: Prof. Levi Chinaka Nwodu, et.al. "Examining Online Posters on Cervical Cancer through the Lens of Extended Parallel Processing Model". International Journal of Media, Journalism and Mass Communications (IJMJMC), vol 6, no. 2, 2020, pp. 01-13 doi: http://dx.doi.org/10.20431/2454-9479.0602001

Copyright: (C) 2020 Authors. This is an open-access article distributed under the terms of the Creative Commons Attribution License, which permits unrestricted use, distribution, and reproduction in any medium, provided the original author and source are credited. 